\title{
Ethylene oxide induces central-peripheral distal axonal degeneration of the lumbar primary neurones in rats
}

\author{
A OHNISHI, ${ }^{1} \mathrm{~N}$ INOUE,${ }^{2}$ T YAMAMOTO,' ${ }^{1}$ MURAI, ${ }^{1}$ H HORI, ${ }^{3}$ M KOGA,${ }^{3}$ I TANAKA,${ }^{3}$ \\ AND T AKIYAMA ${ }^{3}$
}

From the Departments of Neurology, ${ }^{1}$ Environmental Toxicology, ${ }^{2}$ and Environmental Health Engineering, ${ }^{3}$
University of Occupational and Environmental Health, Kitakyushu 807, Japan

ABSTRACT Wistar rats subjected to a single exposure lasting six hours to ethylene oxide (EO) at a concentration of 500 parts per million three times a week for 13 weeks developed ataxia in the hindlegs. Myelinated fibres in hindleg nerves and in the fasciculus gracilis showed axonal degeneration sparing the nerve cell body of the lumbar dorsal root ganglion and myelinated fibres of lumbar dorsal and ventral roots. These pathological findings are compatible with centralperipheral distal axonal degeneration. This is the first animal model of EO neuropathy to be histopathologically verified.

Ethylene oxide $(\mathrm{EO})^{12}$ is widely used as a raw material for industrial chemicals and as a sterilising agent for equipment and supplies, particularly in hospitals. Both the acute and the chronic effects of EO in $\operatorname{man}^{2-5}$ and experimental animals ${ }^{2367}$ are well known. Clinical polyneuropathy after occupational exposure to EO has been reported.$^{8-10}$ These neurological effects may be assumed from animal experiments, ${ }^{67}$ but an animal model of EO induced neuropathy with histological verification has not been documented. We report here the first animal model of EO induced neuropathy characterised by central-peripheral distal axonal degeneration of the primary sensory neurones. ${ }^{1-14}$

\section{Materials and methods}

Ten male Wistar rats each weighing about $250 \mathrm{~g}$ were divided into two groups. Five served as the test animals subjected to a single exposure lasting six hours to EO at a concentration of 500 parts per million (ppm) three times a week for 13 weeks. In some preliminary experiments the methods of exposure and the effects of various concentrations $(250,500,1000$, and $5000 \mathrm{ppm})$ of EO on the body weight and behaviour of the rats were determined. The other five rats, exposed to ambient air in a simi-

Received 29 October 1984

Accepted 26 November 1984 lar manner, were pair-fed and served as controls. All the rats were weighed and examined regularly.

After the completion of the exposure period, the five test rats were killed in pairs with the five control rats by perfusing $3 \%$ glutaraldehyde in $0.1 \mathrm{M}$ cacodylate buffer ( $\mathrm{pH} 7.4)$ under deep pentobarbital anaesthesia. The sural nerve from the same side was harvested at the mid-thigh and ankle level (proximal and distal sural nerve) together with the peroneal nerve above the knee and the tibial nerve above the ankle from each rat. The entire spinal cord with the attached right and left sixth lumbar (L-6) roots and ganglia was dissected out.

Each of the distal sural, proximal sural, peroneal, and tibial nerves was divided into two portions. One portion was postfixed in $1 \%$ osmium tetroxide for two hours, washed, and immersed in $60 \%$ glycerine solution for teased fibre preparations. About 100 teased myelinated fibres were obtained from each specimen and the appearances classified as described by Dyck. ${ }^{15}$ The second portion was additionally fixed in $3 \%$ glutaraldehyde in $0 \cdot 1 \mathrm{M}$ cacodylate buffer ( $\mathrm{pH} \mathrm{7.4)}$ for two hours, postfixed in $1 \%$ osmium tetroxide for two hours, dehydrated, and embedded in epoxy resin. Thick sections $(1.5 \mu \mathrm{m})$ of epon embedded specimens stained with toluidine blue were examined under a light microscope. Photographic enlargements $(\times 1600)$ were obtained to calculate the density (number of myelinated fibres per $\mathrm{mm}^{2}$ of fascicular area) of large (diameter $>5$ 
$\mu \mathrm{m}$ ) and small (diameter $\leqslant 5 \mu \mathrm{m}$ ) myelinated fibres, their size frequency distribution, the total transverse fascicular area $\left(\mathrm{mm}^{2}\right)$, and the number of large and small myelinated fibres per nerve in distal sural, proximal sural, and peroneal nerves. These values were obtained using a particle size analyser (Carl Zeiss TGA-10, West Germany) and programmed calculation and plotting. Student's $t$ test was used for statistical evaluation.

The ipsilateral L-6 ventral and dorsal root ganglia were cut into three parts and embedded in epoxy resin and thick sections were examined under a light microscope.

Transverse slices ( $2 \mathrm{~mm}$ in thickness) of the spinal cord at the level of the third cervical (C-3) and fifth thoracic (T-5) segments were obtained after overnight fixation in $3 \%$ glutaraldehyde in $0.1 \mathrm{M}$ cacodylate buffer from all the rats. The specimens were washed and postfixed in $1 \%$ osmium tetroxide for three hours, dehydrated, and embedded in epoxy resin. Photographic enlargements $(\times 1600)$ of the fasciculus gracilis were obtained to calculate the density (number per $\mathrm{mm}^{2}$ of fascicular area) of myelinated fibres and their size frequency distribution. The area for the determination of the density of myelinated fibres was preselected in the dorsomedian portion of the fasciculus gracilis. ${ }^{14}$

For electron microscopy, thin sections of the epon embedded specimens from both test and control rats were obtained and stained with uranyl acetate and lead citrate. These sections were examined under a Hitachi HS-10 electron microscope at $80 \mathrm{KV}$.

\section{Results}

\section{GENERAL OBSERVATION}

The mean body weights \pm standard deviations in the control and test groups were $247 \pm 6$ and $246 \pm$ $13 \mathrm{~g}$ at the onset and $358 \pm 11$ and $357 \pm 11 \mathrm{~g}$ at the end of the experiment, respectively, with no significant difference between the groups. The mean body weight in the test rats, however, was constantly less 24 hours after each exposure to EO due to poor food intake but similar to the control 48 hours after each exposure to EO due to restoration of food intake.

In the fifth to eighth weeks of the exposure all the test rats showed an awkward gait and three to four weeks before death showed slight to moderate ataxia of the hindleg but without evidence of foot drop or muscle atrophy (fig 1 ).

\section{FINDINGS IN TEASED FIBRE PREPARATIONS}

In all the test nerves the nature of the myelinated fibre degeneration was axonal with linear rows of myelin ovoids. The myelinated fibres showing multifocal breakdown of the myelin sheath (fig 2) were more often detected in the proximal sural than in the distal sural, peroneal, and tibial nerves. Fibres with segmental demyelination and remyelination were never observed. Table 1 shows the mean frequency of myelinated fibres showing linear rows of myelin ovoids or focal myelin breakdown in the test and control groups which were greater in the test animals than in the controls in all the nerves. The difference was statistically significant, except for the proximal sural nerve. The distal sural nerve was more often affected than the proximal sural nerve, but the difference was not statistically significant.

\section{LIGHT MICROSCOPIC FINDINGS OF EPON EMBEDDED PREPARATIONS}

Peripheral nerve - Myelin ovoids were seen in the distal sural, proximal sural, peroneal, and tibial nerves of test rats (fig 3). The frequency of myelinated fibre degeneration appeared to be more prominent in the peroneal, tibial, and distal sural nerves than in the proximal sural nerve. No obvious axonal swellings were observed in these nerves. Mild endoneurial oedema was shown by the appearance of loosely dispersed myelinated fibres with an increase in the transverse fascicular area of both the proximal sural and peroneal nerves of the test rats. Small myelinated axons in clusters suggesting regeneration of myelinated fibres were not found.

Table 2 shows the mean values (with standard deviations) for the total transverse fascicular area (TTFA) and numbers per nerve and median diameter of myelinated fibres in proximal sural, distal sural, and peroneal nerves.

TTFA was significantly greater $(p<0.05)$ in both the proximal sural and peroneal nerves in the test rats but in the proximal sural, distal sural, and peroneal nerves, total, small, and large myelinated

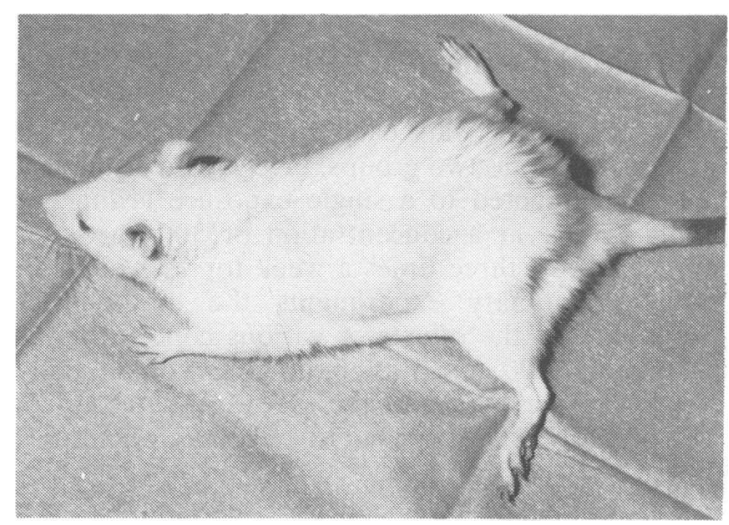

Fig 1 Test rat with an abnormal posture of hindlegs. 


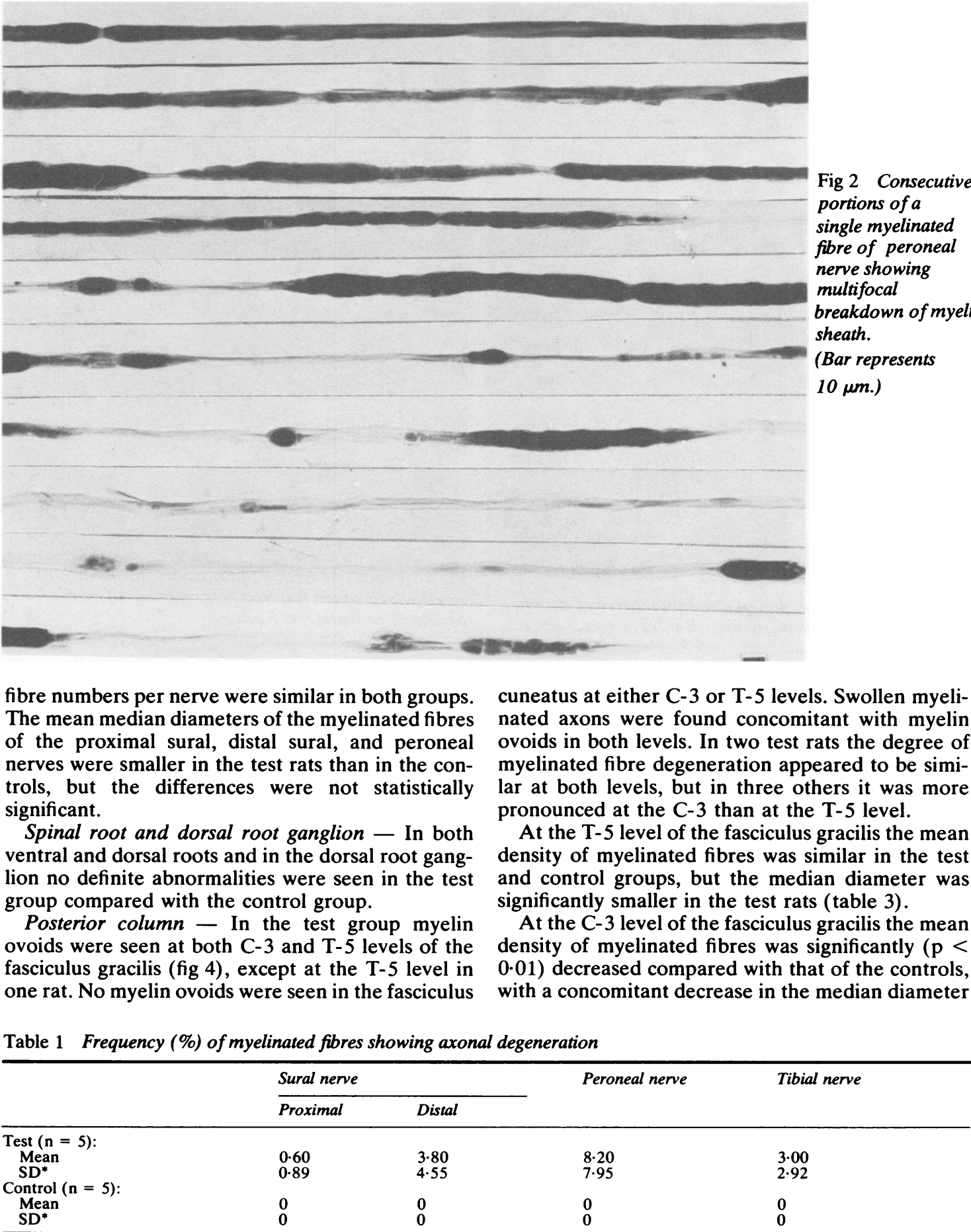

${ }^{*} \mathrm{SD}=$ Standard deviation. 


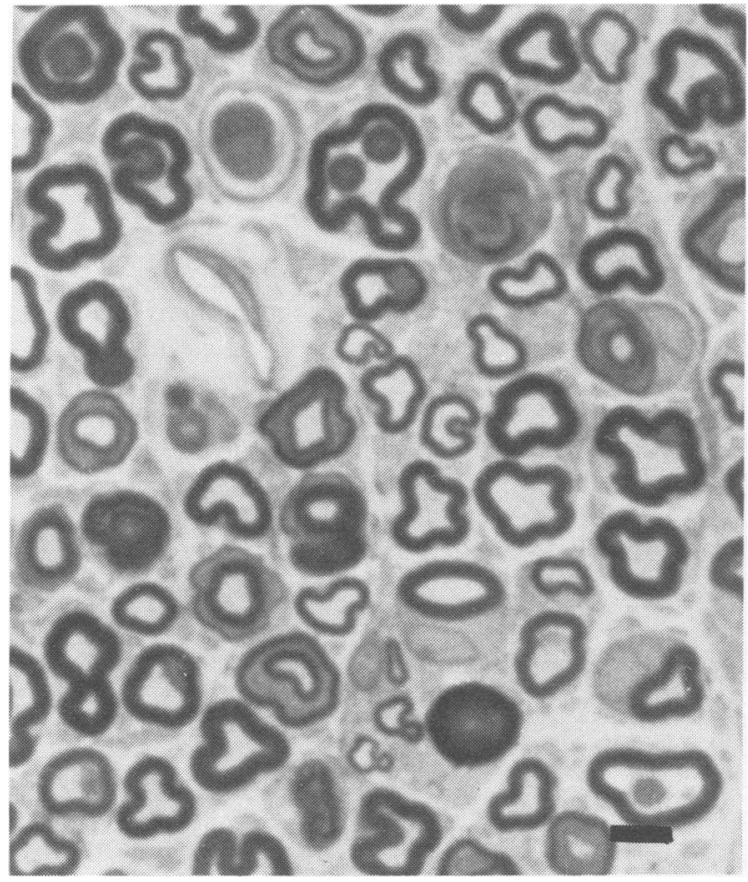

Fig 3 Transverse section of distal sural nerve of test rat. Note presence of myelin ovoids. (Bar represents $5 \mu \mathrm{m}$.)

(table 3). The combined size distribution of the diameters of myelinated fibres in the test group indicated a reduction in the number of myelinated fibres larger than $2 \mu \mathrm{m}$ in diameter, as compared with that in the control group (fig 5).

\section{ELECTRON MICROSCOPIC FINDINGS}

Peripheral nerve - Myelinated fibres showing a granular disintegration of the axoplasmic organelles, with or without myelin breakdown, were found in the peroneal, distal sural, and proximal sural nerves of the test rats (fig 6A); the frequency of such fibres

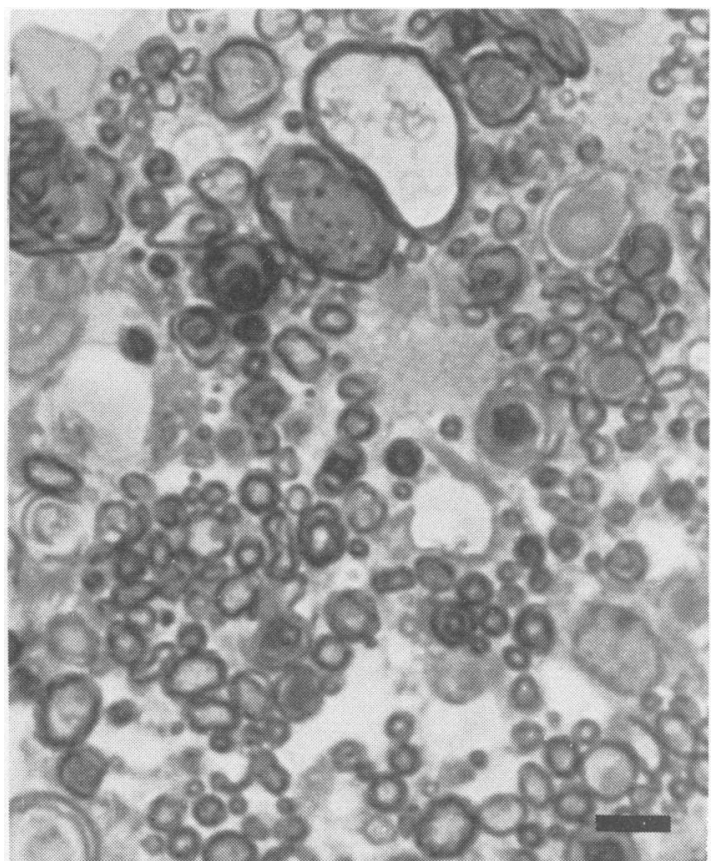

Fig 4 Transverse section of fasciculus gracilis at third cervical level of test rat. Note large number of myelin ovoids. (Bar represents $5 \mu \mathrm{m}$.)

was lowest in the proximal sural nerve. In the degenerating axons the structure of the mitochondria seemed to be relatively well preserved compared with other organelles. In both test and control nerves an obvious accumulation of axoplasmic organelles, such as neurofilaments, tubulomembranous profiles, and vesicular or membranous organelles was not encountered, and there were no. definite abnormalities in the unmyelinated fibres. Denervated Schwann cell cytoplasm without axon was found in the test nerves (fig 6B).

Posterior column - In test rats degenerating

Table 2 Total transverse fascicular area (TTFA) and numbers per nerve and median diameter of myelinated fibres in proximal sural, distal sural, and peroneal nerves

\begin{tabular}{|c|c|c|c|c|c|}
\hline & \multirow[t]{2}{*}{$T T F A\left(\mathrm{~mm}^{2}\right)$} & \multicolumn{3}{|c|}{ Myelinated fibre numbers (No/nerve) } & \multirow{2}{*}{$\begin{array}{l}\text { Median diameter } \\
(\mu \mathrm{m})\end{array}$} \\
\hline & & Total & Small & Large & \\
\hline $\begin{array}{l}\text { Proximal sural nerve test }(n=5) \\
\text { Control }(n=5) \\
\text { Distal sural nerve test }(n=5) \\
\text { Control }(n=5) \\
\text { Peroneal nerve test }(n=5) \\
\text { Control }(n=5)\end{array}$ & $\begin{array}{l}0.0765 \pm 0.0060^{*} \dagger \\
0.0645 \pm 0.0080 \\
0.0579 \pm 0.0100 \\
0.0596 \pm 0.0130 \\
0.2212 \pm 0.0220 \dagger \\
0.2001 \pm 0.0090\end{array}$ & $\begin{array}{r}1244 \pm 192 \\
1113 \pm 193 \\
973 \pm 157 \\
952 \pm 157 \\
1801 \pm 138 \\
1915 \pm 140\end{array}$ & $\begin{array}{l}609 \pm 151 \\
470 \pm 107 \\
516 \pm 102 \\
470 \pm 143 \\
621 \pm 119 \\
606 \pm 168\end{array}$ & $\begin{aligned} 635 & \pm 152 \\
643 & \pm 115 \\
457 & \pm 91 \\
482 & \pm 122 \\
1180 & \pm 216 \\
1309 & \pm 126\end{aligned}$ & $\begin{array}{l}5 \cdot 27 \pm 0.73 \\
5 \cdot 82 \pm 0.45 \\
4.96 \pm 0.33 \\
5.27 \pm 0.78 \\
6.68 \pm 0.59 \\
7.15 \pm 0.80\end{array}$ \\
\hline
\end{tabular}

* Mean \pm standard deviation.

†Significantly $(\mathrm{p}<0.05)$ greater than corresponding control. 
Table 3 Mean of density and median diameter of myelinated fibres of the fasciculus gracilis

\begin{tabular}{|c|c|c|c|c|}
\hline & \multicolumn{2}{|c|}{ Density $\left(\mathrm{No} / \mathrm{mm}^{2}\right)$} & \multicolumn{2}{|c|}{ Median diameter $(\mu \mathrm{m})$} \\
\hline & $T-5$ & $C-3$ & $T-5$ & $C-3$ \\
\hline $\begin{array}{l}\text { Test }(\mathrm{n}=5): \\
\text { Mean } \\
\text { SD* }\end{array}$ & $\begin{array}{l}40187 \\
10216\end{array}$ & $\begin{array}{r}53514 \\
4528\end{array}$ & $\begin{array}{l}2 \cdot 774 \\
0 \cdot 214\end{array}$ & $\begin{array}{l}1.914 \\
0 \cdot 214\end{array}$ \\
\hline $\begin{array}{l}\text { Control }(n=5): \\
\text { Mean } \\
\text { SD }^{*}\end{array}$ & $\begin{array}{r}40800 \\
2 \quad 182\end{array}$ & $\begin{array}{r}61938 \\
8955\end{array}$ & $\begin{array}{l}3.398 \\
0.175\end{array}$ & $\begin{array}{l}2 \cdot 305 \\
0 \cdot 214\end{array}$ \\
\hline $\begin{array}{l}\text { Statistical significance } \\
\text { (Test } v \text { control) }\end{array}$ & NS & $p<0.05$ & $\mathrm{p}<0.01$ & $p<0.01$ \\
\hline
\end{tabular}

*SD = Standard deviation.

myelinated fibres similar to those found in the peripheral nerve were also present. In addition, there were swollen axons containing larger amounts of neurofilaments and vesicular organelles than in
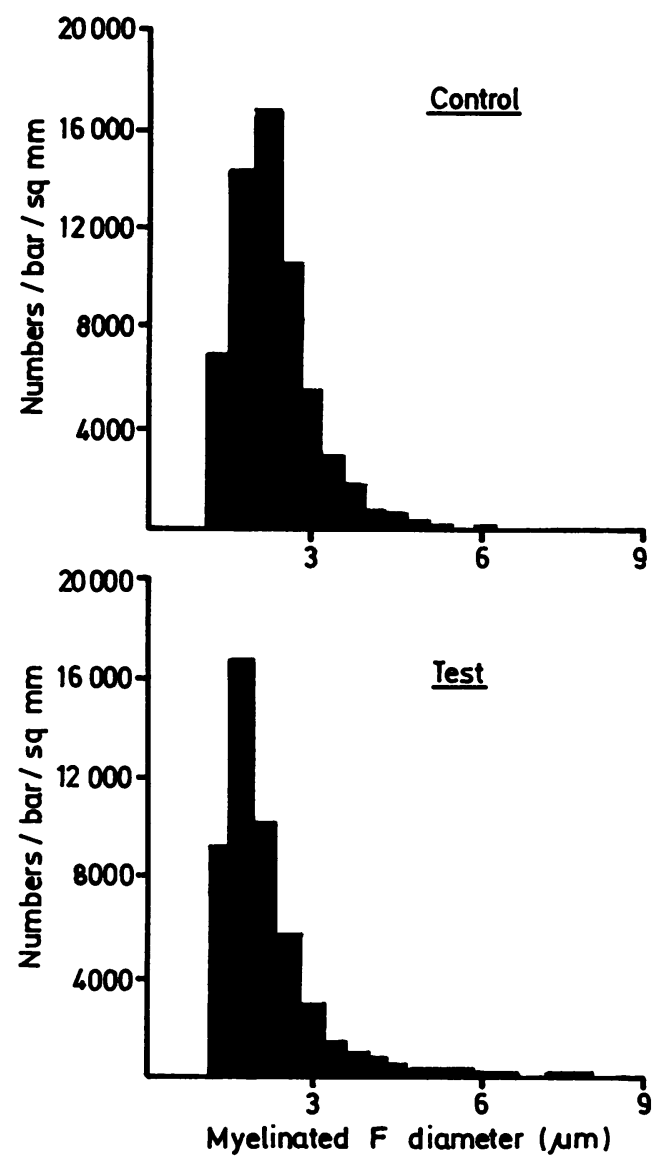

Fig 5 Combined size distributions of diameters of myelinated fibres of fasciculus gracilis at third cervical level in control (upper) and test (lower) groups. the control rats. Astrocytic processes were more prominent in the test than in the control rats, especially at the C-3 level of the fasciculus gracilis.

\section{Discussion}

Clinical cases of polyneuropathy after occupational exposure to EO have been documented..$^{8-10}$ In such cases the clinical signs and symptoms suggest peripheral nerve involvement and there is electrophysiological evidence of axonal neuropathy, with or without histological verification, in addition to the history of chronic exposure to EO. On the other hand, in experimental animals exposed to EO neuropathy with electrophysiological or histological verification, or both, has not been shown, although in monkeys exposed repeatedly 122 to 157 times for 176 to 226 days to EO at a concentration of 204 ppm, partial paralysis occurred, with some evidence of muscular atrophy in the hindlegs. ${ }^{7}$ Rabbits, ${ }^{7}$ rats, ${ }^{6}$ and dogs $^{6}$ also developed paresis of the hindlegs after repeated exposure to EO.

In our study Wistar rats were subjected to a single exposure lasting six hours to $\mathrm{EO}$ at a concentration of $500 \mathrm{ppm}$ three times a week for 13 weeks, and neuropathy was clinically and histopathologically verified. From the clinical point of view, the ataxia of the hindlegs without foot drop or muscle atrophy suggested the involvement of the lumbosacral primary sensory neurone which sends the central axon into the fasciculus gracilis, as seen in other experimental neuropathies. 12141617

The main pathological change was axonal degeneration of myelinated fibres in both the fasciculus gracilis and the hindleg nerve without involvement of the nerve cell bodies in the lumbar dorsal root ganglion and of myelinated fibres in the lumbar spinal roots in the ataxic rats. In the fasciculus gracilis a significant decrease of myelinated fibre density was noted at the C-3 but not at the T-5 level, indicating a more pronounced involvement of the distal central axon of the lumbosacral primary sensory neurone..$^{14}$ 

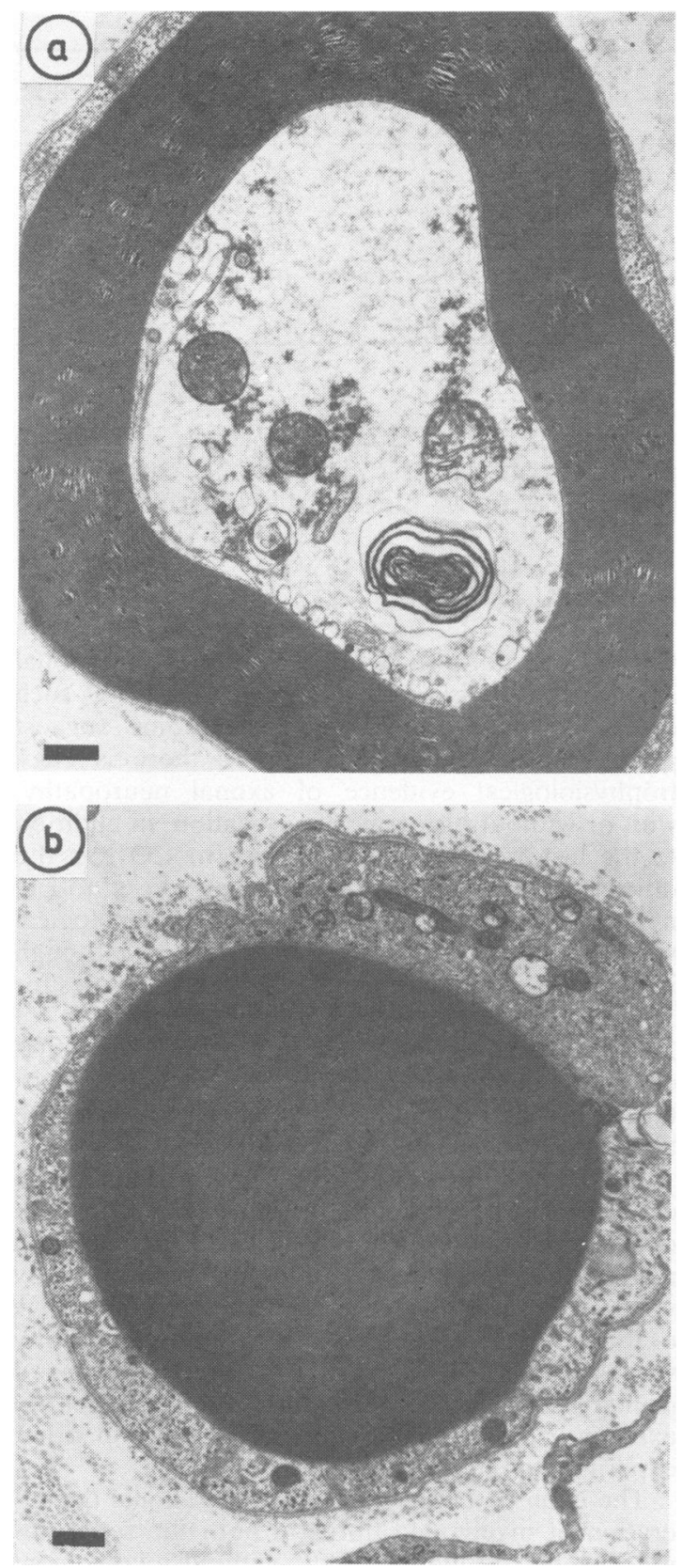

Fig 6 Transverse profles of myelinated fibres of distal sural nerve from test rat, showing (a) granular disintegration of axoplasmic organelles with relative preservation of mitochondria and (b) Schwann cell cytoplasm containing myelin debris without axon. (Bar represents $0.5 \mu \mathrm{m}$.)
The significant decrease in the median diameter of the myelinated fibres at both C- 3 and T- 5 levels was also compatible with axonal degeneration.

In the hindleg nerve the teased fibre analysis showed axonal degeneration common to the sural, peroneal, and tibial nerves. It was more often seen in the distal nerves, such as distal sural, tibial, and peroneal nerves than in the proximal nerve, such as proximal sural nerve. The presence of myelinated fibres with multifocal breakdown of the myelin sheath $^{18-20}$ suggested peripheral nerve involvement along the axon with subsequent axonal degeneration distal to the focal lesions. Such findings in teased fibre analysis are compatible with more pronounced involvement of the distal peripheral nerve, although the frequency of myelinated fibres showing axonal degeneration was less than in some other experimental toxic neuropathies..$^{14} 17$

In the quantitative studies of the myelinated fibres of the proximal sural, distal sural, and peroneal nerves embedded in epoxy resin a preferential decrease in the number of large myelinated fibres, or a preferential decrease in the number of myelinated fibres, was not noted in the distal sural nerve when compared with the proximal sural nerve.$^{14}$ In addition, no decrease in the median diameter of the myelinated fibres was shown in any nerve studied. Therefore, no evidence was found to suggest distal peripheral nerve involvement in epon embedded preparations, probably owing to the low frequency of degenerating myelinated fibres, unlike the case in the teased fibre analysis.

Considering the distribution and frequency of the degenerative findings, the central axons of the lumbar primary sensory neurone (axons in fasciculus gracilis) seem to be more severely affected than the peripheral axons (axons in sural nerve). The difference in the frequency of the degenerative findings between central and peripheral axons is partly explained by the finding that the central axons of the lumbosacral primary sensory neurone with large diameters congregate in the fasciculus gracilis.

With regard to the correlation to the human cases, axonal degeneration in the sural nerve of the test rats is similar to that found in the sural nerve of two patients with EO polyneuropathy. ${ }^{10}$ Furthermore, axonal degeneration in the hindleg nerve of the test rats seems to be compatible with the electrophysiological findings in patients with EO polyneuropathy. ${ }^{8-10}$ Although test rats showed slight to mild ataxia, probably due to the degeneration of myelinated fibres in the posterior column, there were no signs and symptoms suggesting posterior column involvement, except for a preferential decrease of deep sensations compared with superficial sensations in some cases. ${ }^{84}$ 
With regard to the pathogenesis, although there were no particular morphological changes to characterise the nature of the axonal degeneration, such as the accumulation of neurofilaments, ${ }^{1221}$ tubulomembranous profiles ${ }^{1422}$ and vesicular or membranous profiles, ${ }^{23}$ the degeneration of both central and peripheral distal axons of the lumbosacral primary sensory neurone seems to be best explained by the metabolic or toxic effects, or both, of intermediate metabolites of EO. ${ }^{11-1424}$

It is important to be aware of the possible occurrence of EO neuropathy among the potential population exposed to EO in hospitals and in the manufacture of other chemicals.

We thank S Ishimatsu, A Sashihara, R Kaku, and T Kitagawa for technical help and also $M$ Ohara for comments on the manuscript.

Requests for reprints to: Dr Akio Ohnishi, Department of Neurology, University of Occupational and Environmental Health, Kitakyushu 807, Japan.

\section{References}

' Hess LG, Tilton VV. Ethylene oxide. Hazards and methods of handling. Industrial and Engineering Chemistry 1950;42:1251-8.

${ }^{2}$ Glaser ZR. Ethylene oxide: toxicology review and field study results of hospital use. J Environ Pathol Toxicol 1979;2:173208.

${ }^{3}$ Walker WJG, Greeson CE. The toxicity of ethylene oxide. $J$ Hygiene 1932;32:409-16.

${ }^{4}$ Sexton RJ, Henson EV. Experimental ethylene oxide human skin injuries. AMA Archives of Industrial Hygiene and Occupational Medicine 1950;2:549-64.

5 Joyner RE. Chronic toxicity of ethylene oxide. A study of human responses to long-term low-level exposures. Arch Environ Health 1964;8:700-10.

${ }^{6}$ Jacobsen KH, Hackley EB, Feinsilver L. The toxicity of inhaled ethylene oxide and propylene oxide vapors. AMA Archives of Industrial Health 1956;13:237-44.

' Hollingworth RL, Rowe VK, Oyen F, McCollister DD, Spencer HC. Toxicity of ethylene oxide determined on experimental animals. AMA Archives of Industrial Health 1956;13:217-27.

${ }^{8}$ Gross JA, Haas ML, Swift TR. Ethylene oxide neurotoxicity: report of four cases and review of the literature. Neurology 1979;29:973-83.
${ }^{y}$ Finelli PF, Morgan TF, Yaar I, Granger CV. Ethylene oxideinduced polyneuropathy. A clinical and electrophysiologic study. Arch Neurol 1983;40:419-21.

${ }^{10}$ Kuzuhara S, Kanazawa I, Nakanishi T, Egashira T. Ethylene oxide polyneuropathy. Neurology 1983;33:377-80.

"Cavanagh JB. The problems of neurons with long axons. Lancet 1984;i:1284-7.

12 Spencer PS, Schaumburg HH. Central-peripheral distal axonopathy. The pathology of dying back polyneuropathies. In: Zimmerman HM, ed. Progress in neuropathology. New York: Grune and Stratton, 1976:253-95.

${ }^{13}$ Spencer PS, Schaumburg HH. Ultrastructural studies of the dying-back process: IV. Differential vulnerabilities of PNS and CNS fibers in experimental central-peripheral distal axonopathies. J Neuropathol Exp Neurol 1977;36:300-20.

${ }^{14}$ Ohnishi A, Ikeda M. Morphometric evaluation of primary sensory neurons in experimental p-bromophenylacetylurea intoxication. Acta Neuropathol (Berl) 1980;52:111-8.

is Dyk PJ. Pathologic alterations of the peripheral nervous system of man. In: Dyck PJ, Thomas PK, Lambert EH, eds. Peripheral neuropathy. Philadelphia: Saunders Co, 1975:314-9.

${ }^{16}$ Cho E-S, Jortner BS, Schaumburg HH, Spencer PS. A single intravenous injection of doxorubicin (Adriamycin ${ }^{\mathbb{B}}$ ) induces sensory neuronopathy in rats. Neurotoxicology 1979;1:58391.

${ }^{17}$ Ohnishi A, Murai Y, Ikeda M, Kuroiwa Y. Experimental methylmercury intoxication. Morphometric analysis of the nerve fiber of the sural nerve, lumbar spinal roots and Goll's tract. Neurol Med (Tokyo) 1978;9:564-72.

${ }^{18}$ Schaumburg HH, Wisniewski HM, Spencer PS. Ultrastructural studies of the dying-back process. I. Peripheral nerve terminal and axon degeneration in systemic acrylamide intoxication. $J$ Neuropathol Exp Neurol 1974;33:260-84.

${ }^{19}$ Bouldin TW, Cavanagh JB. Organophosphorus neuropathy. I. A teased-fiber study of the spatio-temporal spread of axonal degeneration. Am J Pathol 1979;94:241-52.

${ }^{20}$ Lowndes HE, Baker T. Toxic site of action in distal axonopathies. In: Spencer PS, Schaumburg HH, eds. Experimental and clinical neurotoxicology. Baltimore: Williams and Wilkins, 1980:193-205.

${ }^{21}$ Spencer PS, Schaumburg HH. Ultrastructural studies of the dying-back process. III. The evolution of experimental peripheral giant axonal degeneration. J Neuropathol Exp Neurol 1977;36:276-99.

${ }^{22}$ Blakemore WF, Cavanagh JB. "Neuroaxonal dystrophy" occurring in an experimental "dying-back" process in the rat. Brain 1969;92:789-804.

${ }^{23}$ Chua CL, Ohnishi A, Tateishi J, Kuroiwa Y. Morphometric evaluation of degenerative and regenerative changes in isoniazid-induced neuropathy. Acta Neuropathol (Berl) 1983; 60: 183-93.

${ }^{24}$ Cavanagh JB. The "dying back" process, a common denominator in many naturally occurring and toxic neuropathies. Arch Pathol Lab Med 1979;103:659-64. 